\title{
Comparability of estimates of the impact of gunpowder and gas-dynamic explosions on the stability of buildings and structures
}

\author{
Rasul Tojiev ${ }^{*}$, Elmurad Yunusaliev, and Ibrahim Abdullaev \\ Fergana Polytechnical Institute, Fergana, Uzbekistan
}

\begin{abstract}
A brief description of natural and artificial influences influencing the stability of buildings and structures is presented. Studying the seismic resistance of buildings and structures designed, under construction, erected, and in operation requires time to wait for seismic activity, which is not permissible; costs of manpower and resources, which is inappropriate. In this regard, a working hypothesis has been put forward that by artificially acting on soils with the help of detonation wave energy, it will be possible to induce vibrations, with the help of which it will be possible to study the behavior of building structures put into operation, the entire building and structure as a whole. The goal is set: - to investigate the behavior of structures under construction and in the operation of buildings and structures that perceive artificial vibrations caused by the detonation unit by acting on soils. To achieve this goal, tasks have been identified. A detonation (blast) wave is taken as a "tool" for force action. The theoretical foundations of the experiment are briefly presented and the developed scheme of a detonation tube and a shock wave with a general view of the installation causing detonation wave energy. A brief technique for carrying out field experiments is presented.
\end{abstract}

\section{Introduction}

Studies in $[1,2]$ are devoted to the numerical solution of the problem of transverse and longitudinal vibrations of buildings and structures based on a plate model developed within the framework of the bimoment theory of plates. Using the developed model, the problems of transverse and longitudinal vibrations of buildings and structures were solved in $[3,4]$ within the framework of the bimoment theory of plates.

The physical reliability and new method for the solution of plasticity problems using Ilyushin's approximating relation are described in [5]. A plasticity model for a transversely isotropic material with allowance for complex loading is developed, based on the results of experiments given in [6]. Some plasticity problems regarding complex loading were considered in [7].

In [8], data on the mechanism of tsunami wave formation and destruction were analyzed, and recommendations for tsunami-resistant construction were generalized. A

\footnotetext{
*Corresponding author: gmamatisaev@gmail.com
} 
solution was proposed to mitigate damage from strong earthquakes and high tsunami waves.

The article [9] discusses the main issues for determining the reinforcement parameters of reinforced concrete structures during their inspection. The main known ways of solving these problems were analyzed. The most reliable and accurate methods for determining the parameters of reinforcement were shown.

Under the natural impact on the stability of buildings and structures is meant the seismic effect of earthquakes, research on which is being conducted in all countries in seismically active zones, and sedimentary, subsidence, and landslide phenomena. The "Institute of Mechanics and Seismic Resistance of Structures named after M.T.Urazbayev" and "Institute of Seismology" of the Academy of Sciences of the Republic of Uzbekistan, which has sufficient experience in research work, are closely engaged in the study of this problem in the Republic of Uzbekistan. The Institute has a wide range of information material on powerful earthquakes in Andijan (1947 - 9-10 points), Ashgabat (1949 - 9-10 points), Gazli (1976, 8.04 and 17.05 - 8-9b. And 1984, 20.03 - 9-10b.) And finally, in Tashkent (1966, 26.04.- 8-9b.). In addition, there are results of modern systematic observations of all seismic stations of the Republic [10]. One of the authors of this article conducts his research work at the Institute of Mechanics and Seismic Resistance of Structures.

Artificial influences on the stability of buildings and structures include:

- the action of blast waves, the processes of which are also deeply studied by this institute. An example of this is the wide participation of the authors with the employees of this institute in the blasting operations of the mining industry of the Republic, the study of their impact on the stability of buildings and structures with the receipt of significant scientific and practical information. Of particular note is the practice of studying the action of blast waves in 1966-1980 in the Medeo mountain canyon near the city of Alma Ata. During the three-year period of preparatory work for the explosion (drilling about 10 thousand linear meters. Adits, boreholes and bore-holes and filling over 5 thousand tons of explosive charge) at a safe distance from the epicenter of the explosion, the construction of full-scale frames of experimental residential and public buildings was carried out in parallel [11].

- compulsory oscillatory actions, which include stands, with the help of which it is possible to explore only the models of buildings in several degrees of freedom, creating horizontal and vertical oscillations with different frequencies. These include the unbalance installation of KazNIISA, which causes vibrations through the upper covering of the final floor [12].

Thus, studying the seismic resistance of designed, constructed, erected, and operated buildings and structures requires time to wait for seismic activity, which is not permissible; costs of manpower and resources, which is inappropriate.

In connection with the foregoing, we have put forward a working hypothesis that by artificially acting on soils with the help of detonation wave energy, it will be possible to induce oscillations, with the help of which it will be possible to study the behavior of building structures, laid in the case, of the entire building and structure as a whole.

This work aims to investigate the behavior of structures under construction and in the operation of buildings and structures that perceive artificial vibrations caused by a gas detonation unit. To achieve this goal, the following tasks were identified:

- based on the existing theories and practice of using devices that cause detonation wave energy in various branches of life, develop a gas detonation unit and carry out experiments with it to induce vibrations in soils, buildings, and structures;

- to develop a methodology for conducting experiments using strain gauges, as well as to develop an electronic device for tracking and taking readings; 
- to investigate the degree of influence of detonation wave energy on soils, parameters of structures, buildings, and structures as a whole.

Along with various explosions, as well as with existing expensive installations and stands that create artificial vibrations for buildings and structures, the proposed detonation method for creating vibrations in soils, both in design and construction and in the operation of buildings and structures, opens up several prospects that simplify technical, technological and organizational issues of conducting experiments on the designed and constructed objects, conducting observations of the operated objects with different service life.

The proposed detonation method for creating artificial ground vibrations using a gas detonation unit makes it possible to simplify and accelerate experiments and reduces labor and material costs.

The central idea in our research is the use of a detonation (explosive) wave as a "tool" of force.

The development of the theory and experiment on the detonation of gas mixtures is necessary, firstly, for the correct choice of a theoretical tool in assigning the main design parameters of research, and secondly, for substantiating the scope of research, namely, to exclude from the work the questions that have already been sufficiently well studied. It should be noted that detonation is the process of flame front propagation in gaseous and condensed mixtures of fuel and oxidizer, consisting of a shock wave, a zone of chemical reactions, and a zone of expansion of the products of chemical reactions [13]. This type of combustion, in contrast to the so-called normal combustion, is characterized by high speeds. For example, for most mixtures of hydrocarbon fuels (acetylene, propane, gasoline, etc.) / with air, the flame propagation speed lies in the range of $1600-1800 \mathrm{~m} / \mathrm{s}$, and for concentrated mixtures (such as TNT) - 6000-7000 m/ sec.

Detonation of gas mixtures of conventional fuels (gasoline, gas) with air gives an impulse with the following parameters: - pressure in the shock wave $35 \mathrm{~atm}$.; - flow rate of detonation products $800 \mathrm{~m} / \mathrm{s}$; - movement of the detonation wave along the channel - with speed (as given above) of the order of $1600-1800 \mathrm{~m} / \mathrm{sec}$. - for fuels and $6000-7000 \mathrm{~m} / \mathrm{sec}$. - for TNT.

The systematic scientific study of detonation was initiated by the scientists Berthelot and Viel [14], Malyar, and Le Chatelier [15]. To date, the main provisions of the theory of detonation have been developed in many works.

The qualitative principle of describing the process is that the pipe is closed at one end and filled with a gaseous mixture of fuel and oxidizer. A detonation wave arises at the closed end and propagates to the open end of the tube.

In essence, the process from the moment the detonation wave (DW) appears at the closed end of the tube to the complete outflow of the detonation products (DP) from the tube is divided into slightly different periods. Let's consider these periods in more detail:

- the period of passage of the DW from the closed to the open end of the pipe. During this period, the initial mixture is either at rest and does not flow out of the pipe. It flows out with some initial velocity I0., Pressure, density, and temperature of the initial mixture -P0, p0T0. Behind the detonation wave, there is a certain zone of motion of the DP following the DW. Closer to the closed end of the pipe, there is a rest zone of the PD, in which the PD does not move. Parameters in the rest zone $\mathrm{Pn}, \mathrm{f}$ 1, Tn, $\mathrm{In}=\mathrm{O}$;

- the period of the PD outflow from the pipe from the moment the DW passes through the open end and until the arrival of the first rarefaction wave to the closed end of the pipe. During this period, the pressure on the closed end of the pipe does not change. (Ie $\mathrm{Pp}=$ const);

- the period of critical outflow of PD from the pipe from the moment of reflection of the first rarefaction wave from the closed end of the pipe and until the moment when the 
outflow velocity from the pipe becomes less than critical. During this period, the movement of the PD from the closed end of the pipe occurs at a critical speed, and disturbances from the open end cannot pass against the flow. The parameters at the closed end P3, $\rho$ 3, T3, IZ, during this period are variable;

- the period of the subcritical outflow of the PD from the pipe from the moment when I $<\mathrm{C}$ ( $\mathrm{C}$ is the speed of sound) and until the complete outflow. This period is subdivided into several stages, during which the pressure in the pipe is not only equalized with the pressure in the environment but also a vacuum and a return flow of air from the atmosphere into the pipe are formed. The process is damped periodic.

According to the hydrodynamic theory, the parameters of the initial combustible mixture are distributed from the detonation wave to the detonation products. An arbitrary position of the shock wave along the length of the tube and at the moment of its arrival at the open end is taken. Numerical values are given for mixtures of air with hydrocarbon fuels.

The initial mixture with the parameters Po, $\hat{p}$ o, To, and Io at a short length (almost instantaneously) is compressed by a shock wave (SW). According to LB Zel'dovich's estimates [13], "the front width of a strong shock wave does not exceed the length of one free path" of the molecule.

Let us consider the phenomenon of an explosion of a hot-air mixture in a pipe, in which one end is completely closed, and the other is completely open (Fig. 1).

Let's imagine that the pipe is filled with a mixture of gasoline vapors with air (Fig. 1a). The ratio of gasoline to air is such that the oxygen in the air is sufficient to oxidize gasoline (the so-called stoichiometric ratio); with this ratio, or slightly different from it, a conventional carburetor internal combustion engine works. The pressure of the mixture $\mathrm{P}$ is equal to atmospheric ( $\mathrm{P} 0)$, the temperature $\mathrm{t}$ is assumed to be equal to $/=+20^{\circ} \mathrm{C}$, the mixture is at rest (its speed "IF * is zero). These parameters are reflected in the graph in Fig. 2a.

Let us assume that at the closed end of the pipe, we set fire to the mixture quite intensively, for example, by a strong electric discharge. It is possible to select the discharge power in such a way that explosive combustion (detonation) begins immediately. In fig. $2 \mathrm{~b}$ shows the state of the gas parameters in the pipe at the moment when the explosive combustion spread from the closed end of the pipe to a distance 1. In the pipe section where the combustion has not yet reached (in Fig., the mixture velocity Uo is equal to the initial (as in Fig. 1a) values. There are no changes in this part. In the section of the pipe, at a distance of 1 from the closed end, there is a shock wave - a very narrow, of the order of several $\mathrm{mm}$, zone in which the mixture is compressed to a pressure of $\mathrm{Pv}=35 \mathrm{~atm}$. From this compression, the mixture is heated to approximately the temperature tyB $=15000 \mathrm{C}$. 
a)

б)
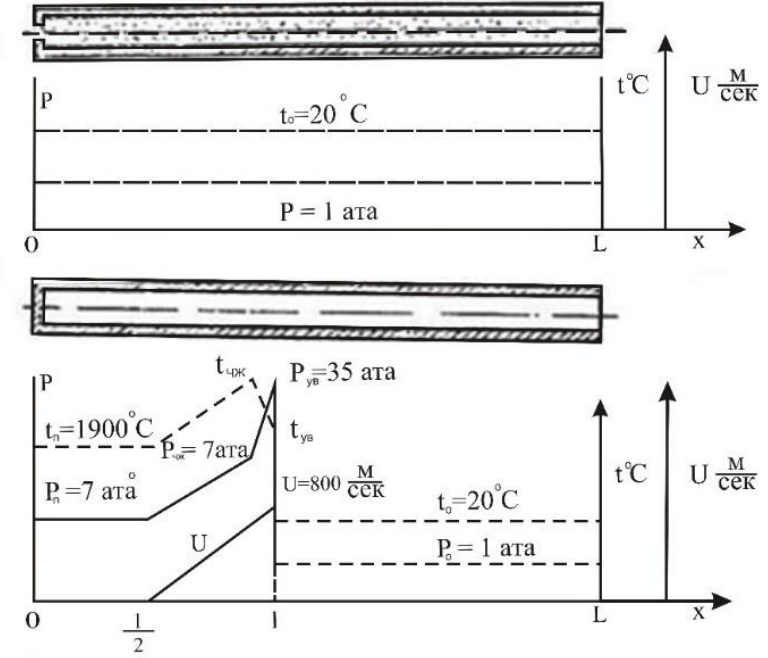

B)
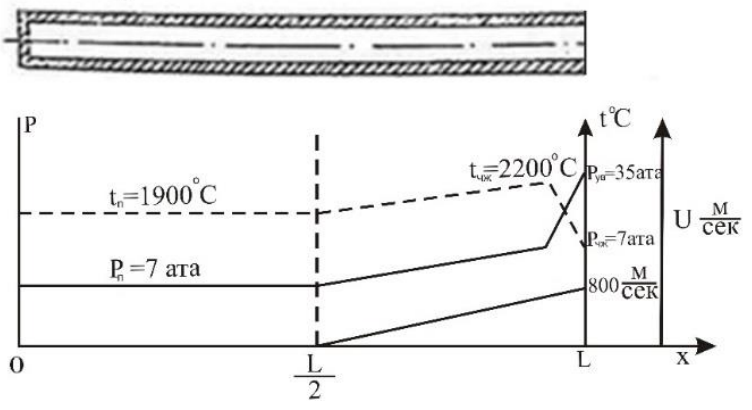

Fig.1. Scheme of filling the pipe with a gaseous mixture

Naturally, from such a temperature, the mixture ignites, and after a short period of time completely burns out, the temperature of the combustion products becomes equal to $t \mathrm{~h} . \mathrm{zh}$. $=2000^{\circ} \mathrm{C}$, pressure P h.zh $=17 \mathrm{~atm}$. Index "h.zh." denotes a special zone where the combustion of the mixture ends: it is taken from the initial letters of the names of scientists Chapman and Jouguet - researchers of detonation combustion.

Behind the shock wave from the side of the closed end of the pipe, the combustion products no longer rest as a fresh mixture but move towards the open end of the pipe at a speed of about $\mathrm{U}=800 \mathrm{~m} / \mathrm{s}$.

The studies in [20-22] are devoted to improving the box-type model of the building structure, taking into account the contact conditions between the elements of the panels and beams. Equations of motion of box-type elements and graphs of displacements of plates and beams are constructed. The article deals with the problem of forced vibrations of a building of spatial box type, which consists of rectangular panels and interacting beams under a dynamic action given by the foundation displacement according to the sinusoidal law. The method of finite differences was used to solve the problem.

On the pipe section from $\mathrm{C}$ to 1 , a change in $\mathrm{P}, \mathrm{t}$, I occurs - approximately as shown in Fig. $1 \mathrm{~b}$ in the cross-section of the pipe at a distance from the closed end - the so-called rest zone is established. The rate of combustion products here is zero; the pressure is of the order of $\mathrm{Pp}=7$ ata, the temperature is slightly below $\mathrm{th}$.zh. and is equal to $\mathrm{tn}=1900^{\circ} \mathrm{C}$. 


\section{Methods}

\subsection{Mathematical models of the problem}

The shock wave moves along the pipe at a speed of $\mathrm{D}=1800 \mathrm{~m} / \mathrm{s}$ towards the open end. In theory, this velocity is called the detonation velocity and is denoted by the letter D. When the shock wave approaches the open end of the pipe, it "burns" the entire mixture, and the parameters shown in Fig. 2 are set in the pipe. 2c, namely: pressure $P p=7$ atm at length $\mathrm{L} / 2$ and increasing to the open end to $\mathrm{Pp}=17 \mathrm{~atm}$; the speed of movement of combustion products, increasing in the section $\mathrm{L} / 2+\mathrm{L}$ up to $800 \mathrm{~m} / \mathrm{s}$ - temperature up to $\mathrm{t}$ h.zh. $=1900^{\circ} \mathrm{C}$; narrow compression zone $\mathrm{Pв}=35$ ata. The time during which the entire mixture burns out is equal to $\mathrm{L} / \mathrm{D}$ (if the pipe is $1 \mathrm{~m}$ long, the time is $1 / 1800 \mathrm{~s}$, if $3 \mathrm{~m}$; the time is $3 / 1800=1 / 600 \mathrm{~s}$ ). As you can see, combustion occurs almost instantly, and a significant amount of energy is generated in the volume of the pipe in the form of potential (pressure of combustion products), kinetic (movement of combustion products), kinetic (movement of combustion products at speeds up to $800 \mathrm{~m} / \mathrm{s}$ ) and thermal (hot combustion products ). Note that no catastrophically high forces arise in this explosion, and it is quite possible to cope with it; an ordinary water pipe can withstand it. If we can organize explosions, following one after another, we get an explosive-type energy generator that works as long as we want, like a conventional internal combustion engine.

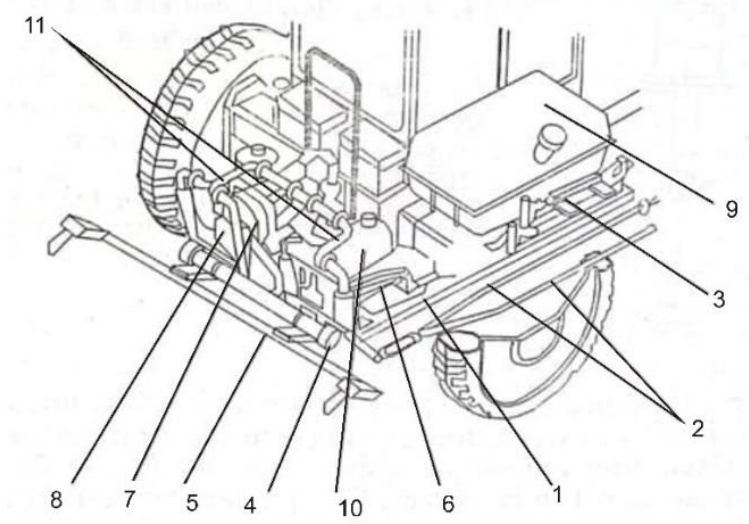

Fig. 2. General view of the installation causing detonation wave energy: 1 is frame; 2 is detonation tube; 3 is hydraulic cylinder; 4 is combustion chamber; 5 is frame; 6 is hydraulic cylinder; 7 is compressor; 8 is compressor motor-chain transmission; 9 is main fuel tank; 11 is pipeline of a combustible air mixture.

The amount of energy released in every single explosion is regulated by the amount of mixture in the pipe. For a more visual representation of such explosive tubes as a source of energy, one can compare them with internal combustion engines in which exhaust occurs during decompression, similar to an explosion with a shock wave. A car with a four-stroke engine, the working volume of which is eight cylinders equal to 6 liters, filled with a fuelair mixture, at an engine speed of $1800 \mathrm{rpm}(30 \mathrm{rpm}$ ), it uses $61 \cdot 30 / 4=4.5$ liters of mixture per second. Such an amount of the mixture can be burned in 9 blast tubes operating at a frequency of 5 times/sec each, $25 \mathrm{~mm}$ in diameter and $2 \mathrm{~m}$ long [16].

Figure 3 shows a diagram of a detonation tube and a shock wave. Here, through the supply system 1, the combustible mixture enters the pipe. In the pipe, the valve 2 located in the inlet part of the combustion chamber 3 provides it with a new mixture and does not allow the combustion components in the cycle of the working stroke to penetrate upstream. 
The combustion process is carried out through a sparking system (spark plug) 7 and an initiating system 8 . To protect the spark plug from a high-speed gas flow, it is protected by a cylindrical shield 4 . To accelerate the combustible flame, a turbulator 5 is placed in series in the pipe structure. The main working volume of the detonation generator, where the combustion process occurs, is pipe 6 . The combustion product under high pressure leaving the open end of the pipe has an alternating effect on the ground. This cycle is repeated, creating a shock wave, followed by instrumental and instrumental observations.

Figuratively speaking, $20 \%$ of the energy released by the engine is concentrated in a relatively small blast tube in the form of potential (pressure), kinetic (flow movement), and thermal (temperature) energies, which can be used for various purposes, including to create ground vibrations. The ongoing experimental research aims to study the nature of the above phenomenon to create artificial ground vibrations using a gas detonation unit [17].

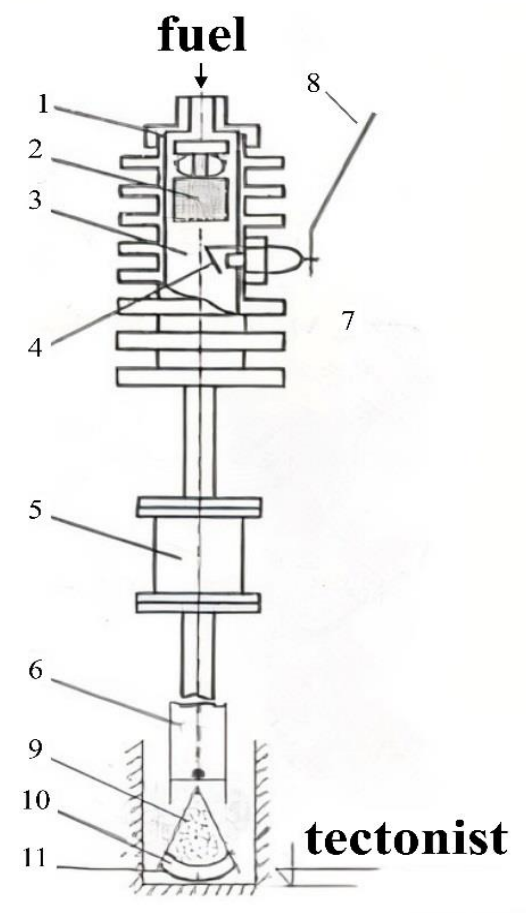

Fig.3. 1 is system for supplying a combustible air mixture; 2 is valve shutting off the flame; 3 is combustion chamber; 4 is screen-foot; 5 is turbulator; 6 is pipe; 7 is candle; 8 is initiating system; 9 is product of combustion; 10 is compressed air; 11 is shock wave

In this regard, experimental studies are being carried out to select the power of this unit, the optimal type, composition, and amount of fuel for its effective use.

In parallel with these works, experiments are underway to develop an electronic device for taking readings from detonation wave action on buildings and structures. And at present, according to the existing and additionally developed methods, the following fullscale tests of structures of buildings and structures have been organized:

1. A set of measuring equipment has been selected, consisting of measuring sensors (seismometers), recording devices (light-beam oscilloscopes), a power supply, connecting lines of sheet piling boxes (Figure 4). 
Block diagram of measuring channels.

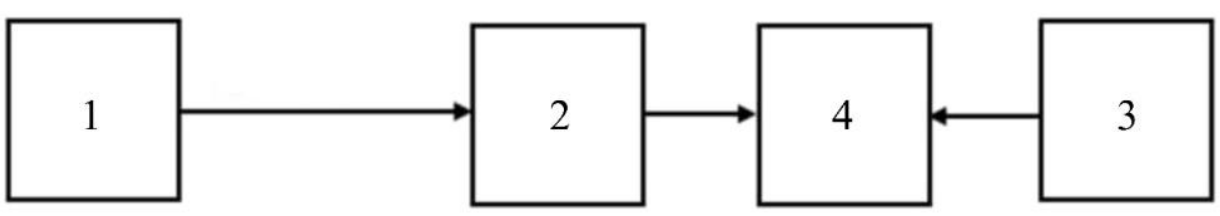

Fig.4. 1 zre sensors; 2 are sheet piling boxes; 3 are power supplies; 4 are oscilloscopes.

\section{Results and Discussion}

To register the parameters of weak and strong movements of soils, buildings, and structures under dynamic influences, seismic sensors such as SM-3, VEGIK, S-5-S, VBP-3, OSP-2M, APT-1, which are used in coupled with low-frequency and high-frequency galvanometers type GB-III and GB-IV. The measuring channels are organized depending on the studied dynamic processes. Records are made on photosensitive oscillographic paper, which is an oscillogram of the measured values after chemical processing. The necessary information, characteristics of the complex of seismometric equipment, and the features of their use are given in [18].

Following the basic requirements and operating conditions of devices [19], before carrying out field experiments in the field to study the vibrations of the ground, buildings, and structures, all measuring equipment is checked, adjusted, and calibrated measuring channels. The measuring channels are calibrated in two ways: by the analytical method of damped vibrations and by pumping the instruments on a special vibration stand.

When using the analytical method, after carrying out preparatory work and installing sensors at observation points, five parameters are preliminarily determined for each organized measuring channel (Fig. 4). Methods for their determination and all the necessary characteristics of the measuring channels for processing the obtained vibration records are detailed in [18.19].

The expressions for the scales of the measuring channel are determined by the values of the sensitivity of the seismometer and galvanometer, their own period and damping of oscillations, as well as the total resistance of the electric circuit (Fig. 1). The vibration amplitudes on the recording, depending on the frequency, will be increased compared to the object vibration amplitudes by a factor of $(\mathrm{V} 0=\mathrm{U}(\mathrm{T}))$. Determination of the value of the expression $(\mathrm{V} 0=\mathrm{U}(\mathrm{T}))$ depending on the amplitude and frequency of oscillations when processing records by the analytical method of damped oscillations is carried out using the calculation formulas [18, 19].

As an example, Figure 6 shows the amplitude-frequency characteristics and channel magnifications obtained based on data from seismometric measuring channels. These results were used in carrying out field experiments.

When pumping the sensors on a vibration table under laboratory conditions, the most reliable result is obtained because the largest number of possible errors and parameter scatter are taken into account. But on the other hand, the characteristics of calibrated instruments during long-distance transportation can change, which will lead to a change in the calibration values of the seismometric measuring channels. 
Electrical diagram of the calibration of measuring channels on a special vibration stand

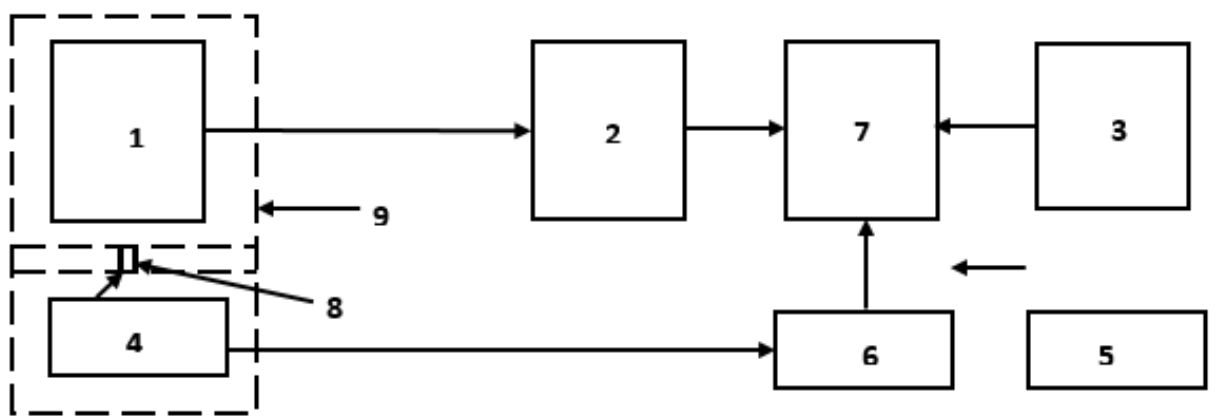

Fig.5. 1 are seismic sensors; 2 is sheet pile box ШК-2; 3 is P-001 power supply unit; 4 is strain gauge sensor; 5 is power supply unit AGAT; 6 is amplifier TOPAZ -3M-01; 7 is oscilloscope - N-041; 8 is indicator ICh10MN; 9 is shaker.

Therefore, when carrying out field experiments in remote regions, we applied the analytical method, and when carrying out frequently repeated experimental studies at close distances, undoubtedly, the calibration method on a vibration stand has an advantage.

When calibrating the measuring channels on the shaker, it is necessary to establish the relationship between the vibrations of the shaker platform and the records obtained on the oscillograms, i.e., build curves of the amplitude-frequency characteristics of the measuring channels. To calibrate the equipment on a vibration stand at various amplitudes and frequencies of platform oscillations in the "DPS" laboratory of the IMISS AS RUz, we have developed an improved method for calibrating measuring channels using highly sensitive sensors based on strain gages. The novelty of the developed calibration technique for measuring channels lies in the combined use of seismometric and strain gauge measurement systems (Fig. 5).

To measure the amplitude of vibrations, a special strain gauge sensor has been developed, consisting of an elastic steel leaf spring with a thickness of $\delta=0.08 \mathrm{~mm}$ and a width of $\mathrm{a}=10 \mathrm{~mm}$. The sensor's length is selected so that, when installed on a platform, the sensor in the measured range ensures operation in the elastic region and sufficient sensitivity of the calibrated channel. First, to manufacture the sensor, the plate's surface is ground to zero roughness, degreased with acetone or industrial alcohol. Then the strain gauges are glued with BF-2 glue on both sides of the plate (strictly parallel in the direction of location), making it possible to double the sensor's sensitivity when assembling according to the half-bridge circuit. In the manufacture of the sensor, strain gauges of the 2PKB-20-200B brand were used with a working base $1=20 \mathrm{~mm}$ and a resistance $\mathrm{R}=200$ om.

To install the manufactured strain gauge sensor on a vibration stand, holes with a diameter of $\mathrm{d}=3.0 \mathrm{~mm}$ were made along the edges of the sensor at a distance of $5 \mathrm{~mm}$. Through these holes, with the help of a screw, one end of the sensor plate is fixed to the stationary post of the shaker, and the other end to the moving part, i.e., on the stand platform (Fig. 5). In parallel with the strain gauge between the stationary and the moving parts (platform) of the shaker, a dial indicator of the ICh10MN brand with a division value of $0.01 \mathrm{~mm}$ is installed. Then, according to the electrical diagram shown in Fig. 5, the assembly of the measuring equipment complex is carried out. The manufactured special sensor registers the movements of the shaker platform at different amplitude-frequency ranges, achieved by changing the platform arm. The content of the novelty of the proposed calibration method of measuring channels according to the electrical diagram shown in Fig. 5 is described below. The technique makes it possible to obtain oscillations with a frequency of up to $-30 \mathrm{~Hz}$ and an amplitude of up to several $\mathrm{cm}$. Based on the data 
obtained, calibration curves were constructed: "movement of the structure (mm) deflection of the oscilloscope beam $(\mathrm{mm})$ " and the magnification factors of the strain gauge measuring channel (ft) were calculated.

After calibration of the strain gauge measuring channel, the sensors are installed on the observed structure and reporting the initial displacement, while the information from the seismic and strain gauge sensors is recorded. Based on the calibration data of the strain gauge measuring channel and the obtained vibration records, the magnification factors are determined for all seismometric measuring channels, depending on the amplitudefrequency characteristics of the vibrations of the building structure.

Following the requirement for the operation of the equipment,

According to the above method, recalibration of the measuring channels, after each experiment with dynamic influences with an intensity of more than 4 points.

Thus, all the necessary preparatory work has been carried out for carrying out field experiments to register the effect of detonation vibrations on buildings, structures, and soil in the field.

Tables 1 and 2 show the rates of ground displacement under induced wave action for various types of buildings and structures.

Table 1.

\begin{tabular}{|c|l|c|}
\hline № & \multicolumn{1}{|c|}{ Buildings and constructions } & $\begin{array}{l}\text { Speed, } \\
\text { sm } / \mathrm{s}\end{array}$ \\
\hline 1 & Large-panel residential buildings & $1.5 / 3$ \\
\hline 2 & $\begin{array}{l}\text { Residential and public buildings of all types (except for large-panel); } \\
\text { administrative and household and industrial. building }\end{array}$ & $3 / 6$ \\
\hline 3 & $\begin{array}{l}\text { Administrative and industrial buildings, high-rise pipes, railway } \\
\text { tunnels, transport overpasses }\end{array}$ & $5 / 10$ \\
\hline 4 & $\begin{array}{l}\text { One-story industrial buildings with metal, reinforced concrete, and } \\
\text { monolithic frames; hydraulic structures; tunnels; }\end{array}$ & $12 / 24$ \\
\hline
\end{tabular}

Table 2.

\begin{tabular}{|c|c|c|c|c|}
\hline $\begin{array}{c}\text { Intensity } \\
\text { in points }\end{array}$ & $\begin{array}{c}\text { Ground } \\
\text { displacement } \\
\text { under wave } \\
\text { action, mm }\end{array}$ & $\begin{array}{c}\text { Ground } \\
\text { displacement } \\
\text { velocity under } \\
\text { wave action, sm / } \\
\text { s }\end{array}$ & $\begin{array}{c}\text { Acceleration of the } \\
\text { amount of soil } \\
\text { under wave action, } \\
\mathrm{sm} / \mathrm{s}^{2}\end{array}$ & $\begin{array}{c}\text { Acceleration of the } \\
\text { amount of soil } \\
\text { during an } \\
\text { earthquake, } \mathrm{sm} / \mathrm{s}^{2}\end{array}$ \\
\hline 3 & $0.14-0.27$ & $0.4-0.8$ & $12-24$ & $3-6$ \\
4 & $0.27-0.5$ & $0.8-1.5$ & $24-45$ & $6-12$ \\
5 & $0.5-1.0$ & $1.5-3.0$ & $45-90$ & $12-25$ \\
6 & $1.0-2.0$ & $3.0-6.0$ & $90-180$ & $25-50$ \\
7 & $2.0-4.0$ & $6.0-12.0$ & $180-360$ & $50-100$ \\
\hline
\end{tabular}

Currently, extensive research is being carried out on the proposed methodology following the list of objects presented in Table 2, the results of which will be provided with relevant information.

\section{Conclusions}

Ongoing studies to study the effect of ground vibrations from detonation waves, instead of explosive and bench methods, significantly accelerate technology and organization, reduce labor, time, and material costs for generating ground vibrations, which in turn accelerates the processes of studying the effect of ground vibrations on seismic resistance buildings and structures. 


\section{References}

1. Usarov D, Turajonov K and Khamidov S, Simulation of free vibrations of a thick plate without simplifying hypotheses, Journal of Physics: Conference Series 1425012115 DOI:org/10.1088/1742-6596/1425/1/012115. (2020)

2. Usarov M K, Buckling of orthotropic plates with bimoments Magazine of Civil Engineering (St. Petersburg, Peter the Great St. Petersburg Polytechnic University) 53 (1) pp 80-90 DOI: 10.5862/MCE.53.8 (2015).

3. Usarov, M., Salokhiddinov, A., Usarov, D.M., Khazratkulov, I., Dremova, N. To the theory of bending and oscillations of three-layered plates with a compressible filler. IOP Conference Series: Materials Science and Engineering.. DOI:10.1088/1757899X/869/5/052037. (2020).

4. AbdikarimovR, Usarov D, Khamidov S, Koraboshev O, Nasirov I and Nosirov A. Free oscillations of three-layered plates. IOP Conf. Series: Materials Science and Engineering 883 012058. doi:10.1088/1757-899X/883/1/012058. (2020).

5. Babamuratov, K.S., Abirov, R.A. On Physical Reliability in the Theory of Plasticity. Strength of Materials 33, pp 1-7 doi.org/10.1023/A:1010478208161. (2001).

6. Abirov, R.A. Allowance for complex loading in transversely isotropic solids. J Appl Mech Tech Phy 50, pp 107-111 doi.org/10.1007/s10808-009-0015-0. (2009).

7. Abirov, R.A. On the physical reliability and taking complex loading into account in plasticity. MaterSci 44, pp 512-516 doi.org/10.1007/s11003-009-9114-6. (2008).

8. Belash, T.A., Yakovlev, A.D. Seismic stability of a tsunami-resistant residential buildings. Magazine of Civil Engineering. 80 (4). pp. 95-103. doi: 10.18720/MCE.80.9. (2018).

9. Ulybin, A.V. Inspection methods of reinforcement parameters of concrete structures. Magazine of Civil Engineering. 27 (1). pp. 4-13. DOI: 10.5862/MCE.27.1. (2012)

10. Sagdiev Kh., Yunusaliev E.M. Investigation of the impact of seismic explosive waves on structures and soil environments in mountainous areas. "Machinalar mechanikasining khozirgi zamon muammolari" khorizhlik olimlar ishtirokidagi republic ilmiy-technician conference maruzalari teplami, Toshkent-2004, 7-8 October, pp 280-283. (2004)

11. Sagdiev H., Yunusaliev E. Evaluation of the seismic effect of industrial explosions produced in difficult mining and geological conditions. Uzbek magazine "Problems of Mechanics", (3), p.29-34. (2006).

12. www.net-film.ru>film-8309

13. www.kursiv.kz

14. Zeldovich IA. B. and Kompaneets A S. Detonation theory. Academic Press New York. (1960)

15. Berthelot Vt'cille ${ }_{7}$ Complrend 95, 18 (1-81), Acad, Sei, Paris.

16. Mallard £.,ChatelierH.,Comp. ( rend./lead Sei., Paris, 95, p 145 . (1881).

17. Tojiev R.Zh., Sadullaev Kh.M., Isomiddinov A.S. Application of the gas-dynamic principle in agricultural technology. Fergana, (2017).

18. Tojiev R.Zh., Yunusaliev E.M., Abdullaev I.N. The Amerikan Ways To Study The Impact Of Ground Vibrations From Exhlosions On The Stability Of Buildings And Struktures. The Amerikan Journal Of Interdisciplinary Innovations And Research. 2 (11), Аппаратура и методика сейсмометрических наблюдений в СССР. М.: Наука, 1974, 242c. (2020)

19. Guidelines for the collection, processing and use of engineering and seismometric information. M.: TsNIISK them. V.A. Kucherenko Gosstroy of the USSR, p.50. (1980),

20. Usarov M., Mamatisaev G. Calculation on seismic resistance of box-type structures of 
large-panel buildings IOP Conf. Series: Materials Science and Engineering 971 032041. https://doi:10.1088/1757-899X/971/3/032041.(2020)

21. UsarovM., et al. Building oscillations based on a plate model 2020 IOP Conf. Ser.: Mater. Sci. Eng.883012211. https://doi.org/10.1088/1757-899X/883/1/012211. (2020).

22. UsarovM., et al. Dynamic calculation of boxed design of buildings. IOP Conf. Series: Materials Science and Engineering 883 (2020) 012186. doi:10.1088/1757899X/883/1/012186. (2020). 